\title{
Unmet Aspirations and Urban Malaise
}

\author{
Tomas Hanell ${ }^{1}$ (10
}

Accepted: 14 December 2021 / Published online: 3 January 2022

(c) The Author(s) 2022

\begin{abstract}
This article analyses the gap between human aspirations concerning self-enhancement and corresponding outcomes in ten western European countries. Utilizing individual data for 14,300 respondents from the European Social Survey, four self-enhancement gap metrics are created: (1) the Ambition gap; (2) the Success gap; (3) the Wealth gap; and (4) the Authority gap. The findings suggest that subjective well-being (SWB) appears to be higher in rural than in urban communities. One reason for lower SWB among urban residents relates to their higher aspirations in certain areas of life. However, urban areas are apparently able to meet the financial expectations of their inhabitants far better than rural areas are, whereas an unmet craving for, e.g., success in rural areas appears not to affect SWB at all. Overall, there is a strong association between unmet aspirations and lower satisfaction with life. The added value of this paper is that it goes beyond existing explanations of the reasons behind urban malaise in developed economies.
\end{abstract}

Keywords Subjective well-being · Quality of life · Aspiration-level theory · Urban malaise $\cdot$ Community type

\section{Introduction}

\subsection{Urban Malaise}

In mature economies, subjective well-being — such as happiness or life satisfaction-has rather consistently been observed to be higher in rural than in urban surroundings. Fischer (1973) coined the term "urban malaise" for this phenomenon, whereas Dunlop et al. (2016) used the term "metropolitan misery". People living in large cities aspire to different things than those living in smaller cities or the countryside. The basic hypothesis of this study is that such generic locational differences in the composition and strength of aspirations and their related outcomes should also be able to explain urban-rural differences in subjective well-being.

Tomas Hanell

tomas.hanell@helsinki.fi

1 Faculty of Science, Department of Geosciences and Geography, University of Helsinki, Yliopistonkatu 3, P. O. Box 4, 00014 Helsinki, Finland 
This article thus analyses the gap between human aspirations concerning self-enhancement and corresponding outcomes in ten western European countries. Utilizing micro data from the European Social Survey, I aim at enlarging the palette of explanations behind the syndrome of urban malaise and thus contributing to further understanding of why urban residents report lower subjective well-being than do their rural counterparts. From here onwards I treat the terms quality of life (QoL) and subjective well-being (SWB) interchangeably.

In the discussion which follows, I first introduce some prior evidence of urban malaise and how its existence has been explained up to now. I then proceed to discuss why selfenhancement may be a typical urban trait and how this may be operationalized in a statistical sense. I then present empirical evidence supporting the differing effect that unmet aspirations have on urban and more rural inhabitants and finally discuss what kinds of societal implications these findings may have.

\subsection{Existence of Urban Malaise and its Explanations}

The body of evidence pointing to lower urban SWB in mature economies is rather substantial. For different European countries, this includes the findings of, e.g., Dale (1980), Gerdtham and Johannesson (2001), Sørensen (2014), Gilbert et al. (2016), Migheli (2017), as well as Morrison and Weckroth (2018). Lenzi and Perucca (2018) concluded that mediumrank urban areas in the European Union (EU) have a higher quality of life (QoL) than do the most urbanized regions. Concerning Germany, Bergheim (2008) ended up with similar results. In developed countries outside Europe, evidence of urban malaise includes the studies by Morrison (2010) as well as Rossouw and Pacheco (2012) concerning New Zealand, Dockery (2003) regarding Australia, Choi and Lee (2008) regarding South Korea, as well as the studies by Sander (2011), Lawless and Lucas (2011), Okulicz-Kozaryn and Mazelis (2016) and Winters and Li (2017) concerning the US.

There are a number of studies that contradict the conception of lower SWB in the urban areas of mature economies. They stem primarily from North America (cf. Glaeser et al., 2016; Millward \& Spinney, 2013; Oswald \& Wu, 2010). Pertaining to the EU, Shucksmith et al. (2009) noted that, in richer EU countries, QoL was perceived to be only marginally higher in rural areas than in urban ones, whereas the opposite was the case in poorer countries. Kim (2018) reached a largely similar conclusion for 27 European countries, as did Best et al. (2000) for Australia. Okulicz-Kozaryn and Valente (2019) found that, although there still exists a general SWB gap in favour of rural areas in the US, that gap has begun to decrease. Furthermore, when examining different age groups, they concluded that for persons born between 1982 and 2004, this gap has shifted in favour of urban areas.

Hitherto, the dominant explanations of urban malaise have rested on some variation of what Morrison labelled the "localization of the paradox of affluence" (Morrison, 2010: p. 1040). Cities overall are undoubtedly able to provide for higher material welfare than rural areas do (Glaeser et al., 2016; Veneri \& Murtin, 2018), but as external diseconomies of scale in cities reach a certain threshold, the effect of increased material welfare is no longer able to counterbalance the negative factors of living in a large city. Such negative urban externalities typically listed include environmental problems, congestion, long commutes, expensive and/or crowded housing, crime and insecurity, a poor work-life balance, and high societal tension, as well as greater inequalities (Dunlop et al., 2016; Hanell, 2018).

The relationship between human aspirations and the fulfilment of these aspirations, as well as their effect on SWB, have hitherto been studied primarily at a generic level with 
little reference to place. This article aims at expanding this topic into regional science by incorporating type of settlement into the analysis. I argue that one partial explanation for urban malaise in developed economies relates to urban-rural differences in the discrepancy between inhabitants' aspirations in certain areas of life and the varying degree to which these aspirations are fulfilled.

\subsection{Objectives of the Article}

The three cumulative objectives of this article are as follows.

1. To demonstrate that there exists between urban and rural dwellers in ten western EU countries a discernible difference between the levels of aspiration associated with selfenhancement and the related actual outcome.

2. To corroborate that the discrepancy between aspiration and outcome is associated with levels of SWB, more specifically, overall satisfaction with life.

3. To validate that there are noticeable urban-rural differences in this discrepancy that are capable of explaining parts of the phenomenon of urban malaise.

By doing so, I aim at increasing the knowledge of, and tentative explanations for, the phenomenon of urban malaise in advanced economies. My hypothesis is that if there exist locational differences-in this case generic urban-rural differences-in the composition of aspirations and their relationship to outcomes, one should also expect to find associated differences in subjective well-being between the types of locations.

\subsection{Aspirations and Urban-Rural Differences Thereof}

The aspiration-level theory postulates that if a person obtains what he or she aspires to, then that will have a positive impact on that person's SWB. If, however, aspirations are unmet, then the impact on SWB is likely to be negative. An individual's level of satisfaction is thus "the perceived discrepancy between aspirations and achievement" (Campbell et al., 1976:p. 8), or in the words of Meadow et al. (1992:p. 25), that "the degree of life satisfaction/dissatisfaction experienced is a function of the ratio of fulfilled desires to total desires". Irrespective of the actual level of the outcome, unrealistic or too highly placed expectations may result in lower levels of happiness or satisfaction if the negative gap between aspirations and outcomes becomes wide enough (Frey \& Stutzer, 2002; Mason \& Faulkenberry, 1978). Conversely, if the outcome exceeds the aspiration, that should in turn result in higher levels of SWB.

Two well-studied treadmill effects fuel human aspirations (e.g. Brickman et al., 1978; Heady \& Wearing, 1989; Lucas et al., 2003; Fujita \& Diener, 2005; Kahneman \& Krueger, 2006; or Deaton, 2012). On the one hand, the tendency of people to compare their income, consumption, prestige, or general utility against other persons in their vicinity, labelled by Frank (1985) as the positional treadmill, but colloquially known as "keeping up with the Joneses". This treadmill effect is highly relevant in a geographic context. On the other hand, the tendency of SWB is to re-align itself in accordance with ever-increasing aspiration levels, labelled by Brickman and Campbell (1971) as the hedonic treadmill.

Stutzer (2004) provided a prime example of these two mechanisms. He analysed the effect that income aspirations exerted on overall satisfaction with life in Switzerland. He affirmed that the magnitude of a person's income aspiration correlated positively 
with both his/her actual income and with the level of income in the community the person lived in. Controlling for standard socio-demographic characteristics, he was also able to demonstrate that higher income aspirations were connected to lower levels of overall satisfaction with life. His study was however limited to financial aspirations/ utility alone and did not contain any additional spatial differentiation (beyond controlling for average community income).

Some past studies have demonstrated that urban and rural inhabitants in developed countries indeed differ in their level of aspiration concerning their future. These studies have focused excessively on young people and particularly on their career and educational expectations. Lipset (1956) asserted that rural youth had lower educational and occupational aspirations than their peer city dwellers. Such findings have been corroborated by Middleton and Grigg (1959), by Burchinal (1961), and, more recently, by Andres and Looker (2001). Sewell and Orenstein (1965) additionally noted a similar discrepancy concerning urban and rural boys, but not girls. However, for instance, Bajema et al. (2002) or Howley (2006) did not observe any major corresponding urban-rural differences. In addition, McCray and Day (1977) did not observe any major discrepancy as regards housing aspirations among urban and rural inhabitants.

Concerning an actual rural-urban differentiated impact of aspirational discrepancy affecting SWB, not many studies have hitherto been conducted. In analysing satisfaction related to a large number of different life domains, Amos et al. (1982) noted that the more rural an area was, the lower were the aspirations of its inhabitants and conversely the higher was their satisfaction with most life domains, health constituting the primary exception. In addition, Davis and Fine-Davis (1991) also suggested that the higher overall satisfaction with life of rural residents in six EU countries could tentatively be attributed to lower expectations. More recently, however, little attention has been paid to this phenomenon, although Rentfrow (2018), for example, broadly concluded that aspirations appear to be strongly related to the features of community.

\section{Data and Method}

\subsection{Overall Satisfaction with Life as an SWB Outcome Metric}

The most commonly utilized subjective quality of life outcome metrics are happiness and life satisfaction. The two are frequently used interchangeably (cf. Easterlin, 2001; Veenhoven, 1997). Their mutual relationship is, however, far from straightforward (Bjørnskov et al., 2008). Whereas happiness is oftentimes a temporary affective occurrence, life satisfaction is based on a more long-term cognitive judgement about the overall situation of one's life (Andrews \& McKennell, 1980; Lucas \& Diener, 2009; Organ \& Near, 1985). Due to the differing scope of the two concepts, life satisfaction-although being far from constant at the level of the individual (Ehrhardt et al., 2000)—nonetheless tends to be more stable than happiness (Gelman et al., 2008; Oleson, 1990; Pellenbarg \& van Steen, 2011; Pittau et al., 2010; Zimmermann, 2014). Taking into consideration its wider scope and lesser volatility, the variable "Satisfaction with life as a whole" is utilized as the main SWB outcome metric in this article. 


\subsection{Principal Predictor Variables: Aspirations, Outcomes, and the Distance Between the two}

Humans aspire to many things in life and tend to rank them according to their individual preferences. In the context of this study, it would be pertinent to ask which types of aspirations could be most relevant to a place-sensitive analysis? Are there any typical urban or rural values which transcend others? Schwartz (1994 and 2012) identifies ten types of human values divided into four main groups: self-transcendence; conservation; self-enhancement; and openness to change. Could any of these be more relevant in an urban-rural context than the others?

In the urban economic literature, cities are, apart from being havens of material prosperity, generally portrayed as nexuses of success, accomplishment, innovation, productivity, decision-making, and other similar positive attributes (cf. Acs, 2003; Florida, 2005; Cheshire, 2006; or Glaeser, 2011). Transposed to personal traits, such characterizations resonate well with extrinsic, materialistic goals pertaining to financial success, personal image, and popularity, as defined, for instance, by Grouzet et al. (2005), or corresponding values related to self-enhancement such as achievement and power as identified by Schwartz (1994 and 2012). Okulicz-Kozaryn and Valente state that the "lure to great cities is due in part to people's desire for power and status" (2018:p. 209). Since such materialistically loaded issues have been demonstrated to affect SWB negatively (Graham \& Pettinato, 2001; Richins \& Rudmin, 1994; Roberts \& Clement, 2007), it appears apposite to approach the urban-rural issue first and foremost from the angle of self-enhancement. Choosing this particular viewpoint does not imply that other types of aspirations, such as security, conformity, traditionality or benevolence, would be any less relevant in an urban-rural context.

How then to quantify the quest for power and status? Schwartz argues that personal aspirations are a reflection of a person's values, "values refer to desirable goals that motivate action" (Schwartz, 2012:p. 3). In other words, people on average are likely to strive more for things they attach value to and less for things they do not deem valuable. From here on, I will simply refer to these value-based metrics as aspirations.

Building upon Schwartz's theory of basic human values, I will accordingly examine allegedly typical urban values related to self-enhancement. Schwartz distinguishes between two types of self-enhancement: achievement and power. Achievement relates to ambitiousness and success by displaying personal competence in accordance with prevailing cultural standards. Power in turn relates to prestige and control over people and/ or resources. Both power and achievement relate to social esteem, but in different ways. While the former focuses on an active demonstration of performance, the latter emphasizes a person's perceived position within the general social system (Schwartz, 2012).

The literal survey questions for Schwartz's basic values are stated as follows: "Now I will briefly describe some people. Please listen to each description and tell me how much each person is or is not like you." The original response categories are: $1=$ "Very much like me"; 2 = "Like me"; 3 = "Somewhat like me"; 4="A little like me"; $5=$ "Not like me"; and $6=$ "Not like me at all".

The data set utilized in this study (cf. Sect. 2.3 below) includes only two questions each on both achievement and power, and these four questions constitute the basis of the analysis. The four principal variables concerning self-enhancement used in this article are hence the following: 
1. Ambition aspiration: "It is important to her/him to show her/his abilities. She/he wants people to admire what she/he does";

2. Success aspiration: "Being very successful is important to her/him. She/he hopes people will recognise her/his achievements";

3. Wealth aspiration: "It is important to her/him to be rich. She/he wants to have a lot of money and expensive things";

4. Authority aspiration: "It is important to her/him to get respect from others. She/he wants people to do what she/he says".

Identifying corresponding outcome metrics for these aspirations is, beyond the wealth one, extremely challenging. There exist no precise corresponding outcome variables to the statements listed above, so proxies become a necessity. Suitable outcome variables in the data set relate mostly to the survey's specific module on personal and social well-being. There are a small number of variables like "feeling accomplishment from what one does", "feeling very positive about oneself", "there are lots of things one is good at", or "feeling appreciated by people one is close to" that vaguely relate to ambition or success. These are however personal assessments of oneself which by and large do not reflect assessments made by the surrounding society. Beyond wealth, which can be crudely proxied by household income, there are three additional variables which relate to displaying capability (ambition), perceived societal position (success), and obtaining respect (authority). All remaining variables in the survey's specific module on personal and social well-being relate more to mental and physical well-being and are poorly suited to the purpose of this study. For this article, I hence utilize the following outcome metrics:

1. Ambition outcome: "In my daily life I get very little chance to show how capable I am" (original scale 1-5, where 1 = "Agree strongly" and 5 = "Disagree strongly");

2. Success outcome: "Your place in society" (original scale $0-10$, where $0=$ "Bottom of our society" and 10= "Top of our society");

3. Wealth outcome: "Household's total net income, all sources" (original scale 1-10, where $1=$ " 1 st decile" and $10=$ " $10^{\text {th }}$ decile"); and

4. Authority outcome: "Feel people treat you with respect" (original scale 0-6, where $0=$ "Not at all" and $6=$ "A great deal").

For the re-scaling of all these eight variables, cf. Sect. 2.3. By comparing pairwise each item of aspiration with its corresponding outcome at a similar scale, a numeric indication of an individual's positive (outcomes exceed aspirations) or negative (outcomes fall behind aspirations) gap between aspiration and outcome can thus be obtained. I consequently label these four gaps as (1) the Ambition gap, (2) the Success gap, (3) the Wealth gap, and (4) the Authority gap.

This set-up has an inherent weakness related to time. As it is now, the respondents are asked about aspirations and outcome at the same time. Ideally, they should be asked about their current aspirations for the future, and then, after a suitable time lag, how well these aspirations were actually met. This is especially critical in cases were external positive or negative shocks lead to a re-scaling of one's aspirations. For this purpose, one should use longitudinal surveys in where the same respondent would be asked at least twice. Such longitudinal survey data is to the best of my knowledge not available in any trans-European survey that also includes a regional variable. 


\subsection{Data Operationalization and Analytic Method}

The principal data source for this study is the European Social Survey (ESS) number 6-2012 ed. 2.1, which was published in November 2014 (ESS Round 6: European Social Survey Round 6 Data 2012). This is the most recent survey round to contain a specific module on personal and social well-being questions, which are crucial in order to chart not only aspirations but also the perception of their realization. Since urban malaise appears to be a syndrome in advanced economies alone, the sample of countries is correspondingly restricted to old member states of the European Union (EU) only, all of which could be characterized as mature economies. Twelve Old EU Member States participated in this particular survey round. However, since both Germany and the UK lacked sufficiently accurate regional delimitations of the respondents, only ten western EU Member states were finally included in the data set. These were Finland, Sweden, Denmark, Ireland, the Netherlands, Belgium, France, Spain, Portugal and Italy. In these ten countries, the total number of respondents in the ESS amounted to 19,540 persons. Due to individual non-responses, the effective sample size for the main analysis was between 14,236 and 14,391 respondents.

The analysis is conducted with ordinary least squares regression. The dependent variable "How satisfied with life as a whole" maintains its original eleven-point scale, where 0 equals "extremely dissatisfied" and 10 correspondingly "extremely satisfied".

The principal predictor variables (cf. previous subsection) are recorded at varying numeric scales in the ESS. Reversing the negatively oriented ones, the principal predictors were first normalized to a scale of 1-10 where 1 equals the lowest possible value and 10 the highest. For each respondent, the overall weighted mean of the entire tencountry sample population was then deducted from the value of each specific variable, thereby equalizing the differing sample means (cf. Table 1) for each variable. Finally, the value for the four individual Schwartz self-enhancement aspiration metrics was subtracted from their corresponding outcome metric values, resulting in a positive (=aspirations met or exceeded) or a negative (= aspirations not met) distance between outcome and aspiration.

All data were weighted with post-stratification as well as population size weights to enable calculation of cross-country averages (European Social Survey, 2014). The basic features of all data are presented in Table 4.

Concerning the division of the territory into urban and other areas, the European Commission Typology of Urban-Rural Regions (Eurostat, 2010) was used for data available at NUTS level 3. For those countries where data were available at NUTS level 2 only, the corresponding classification by Jonard et al. (2009) was applied. The original classification is based on three categories: "Predominantly urban", "Intermediate", and "Predominantly rural" regions. For the ten sample countries of this study, as many as 31 out of all 40 regions classified as "Predominantly rural" are located either in one of the three Nordic countries or in Ireland. This is expected to create a substantial bias in the results, which entails a necessity to merge the two groups "Intermediate" and "Predominantly rural" regions into a single ("non-urban") class. In effect, this implies that out of altogether 137 regions in the ten concerned countries, 32 are classified as predominantly urban. There is at least one such region in each country. In smaller countries it is typically the capital metropolitan region, in larger or more densely populated countries (such as in Italy, Spain, the Netherlands or Belgium) there are several metropolitan areas. 


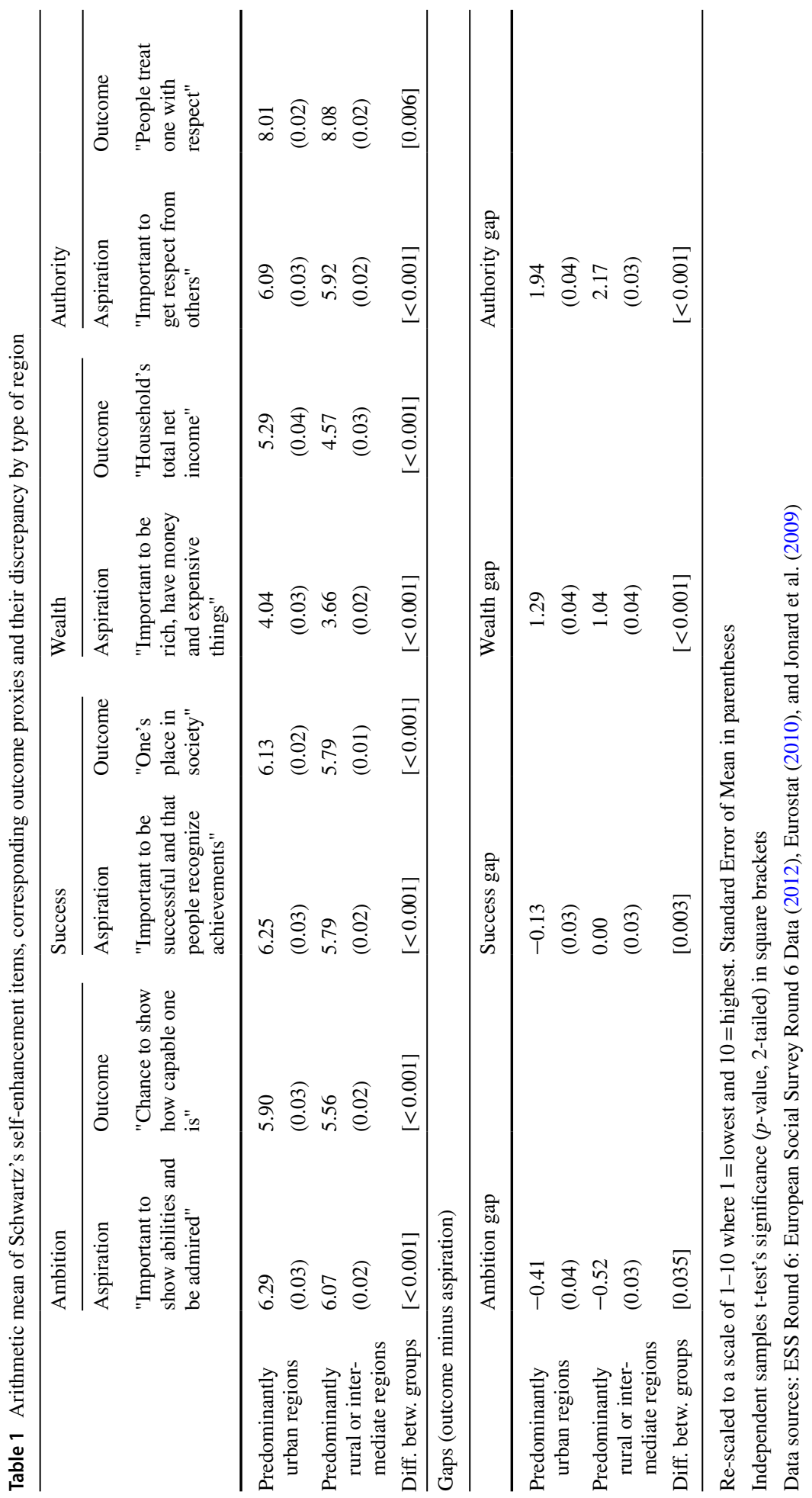


In order to address the apparent challenge of geographically extensive and settlementwise heterogeneous NUTS 2 and NUTS 3 regions, additional control variables for subjectively reported domicile (i.e., "countryside", "village", etc.) are also included.

In this urban-rural setting, the positional treadmill also requires attention. The primary reference group for urban residents is mostly other urban residents, and for rurals consequently mostly other rurals. However, someone recently migrated to a city might still maintain her/his former rural reference group, thereupon affecting aspirations either positively or negatively. Ideally, one should also be able to control for this aspect. Unfortunately, the data set used herein does not allow that.

In addition to controlling for most evident country differences, the remaining control variables include standard individual characteristics that have been extensively proven to be associated with SWB, such as gender, age, household characteristics, health, education, and labour market status (Dolan et al., 2008). The practical operationalization of these control variables is described in Table 2 .

As an additional confirmation of robustness, the final stages of the analysis also introduce control variables for the actual levels of both aspiration and outcome. In order to avoid collinearity, these controls are included as dummy variables where each aspiration and outcome variable has been divided in three equal parts. For each variable, the middlemost tertile is used as the reference group, and the most negative and the most positive thirds respectively as dummy variables. This procedure enables eliminating their possible effect on SWB and focuses the analysis purely on the gap between aspiration and outcome.

\section{Findings}

Corroborating existing evidence, Table 1 demonstrates that aspirations in urban areas appear higher than in rural. The largest urban-rural difference in aspirations concerns the two metrics related to success and wealth respectively. The remaining two concerning ambition and authority are nevertheless also on average higher in the most urbanized areas.

However, not only aspirations but also the corresponding outcomes are for the most part higher in urban areas than in rural ones, thereupon diminishing the urban-rural differences vis-à-vis fulfilment of aspirations. The only exception to this pattern concerns authority, where rural residents on average state higher outcomes than do urban ones. Thus, on the whole, Table 1 substantiates the assumption of the first objective, i.e., that urban and rural dwellers aspire differently, and that the actual outcomes also differ.

The metrics in the table further indicate-for urban and rural residents alike- that the gap between aspiration and outcome would on average be negative concerning ambition and success, and positive concerning wealth and authority. The latter case can, however, not be interpreted so that the expectations of most respondents would on average actually have been exceeded. This numeric excess may simply be the effect of the normalization method used for the metrics, the original scale of the data, and the scale the data is now superimposed on. What can be said though is that, for an individual respondent, the more positive the measured distance of outcome minus aspiration is-or conversely the less negative it is - the better the aspirations of that respondent have been fulfilled.

The mere facts that urban and rural dwellers aspire differently and that the outcomes differ do not yet explain whether urban inhabitants are reporting lower SWB due to this. The next step of the analysis takes us a bit further on that inquiry, as Table 2 presents three multiple regression models with overall satisfaction with life as the dependent variable. 


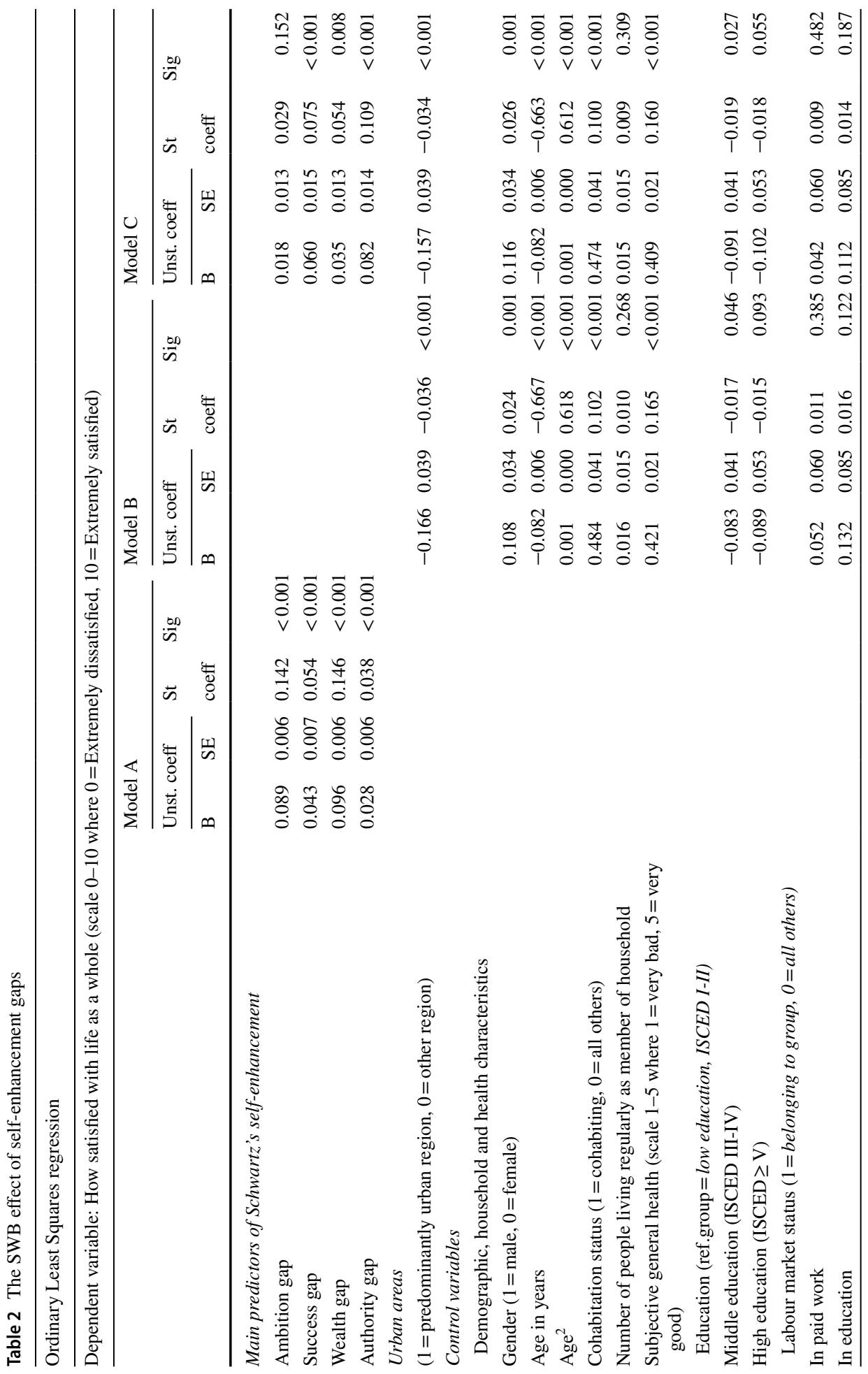




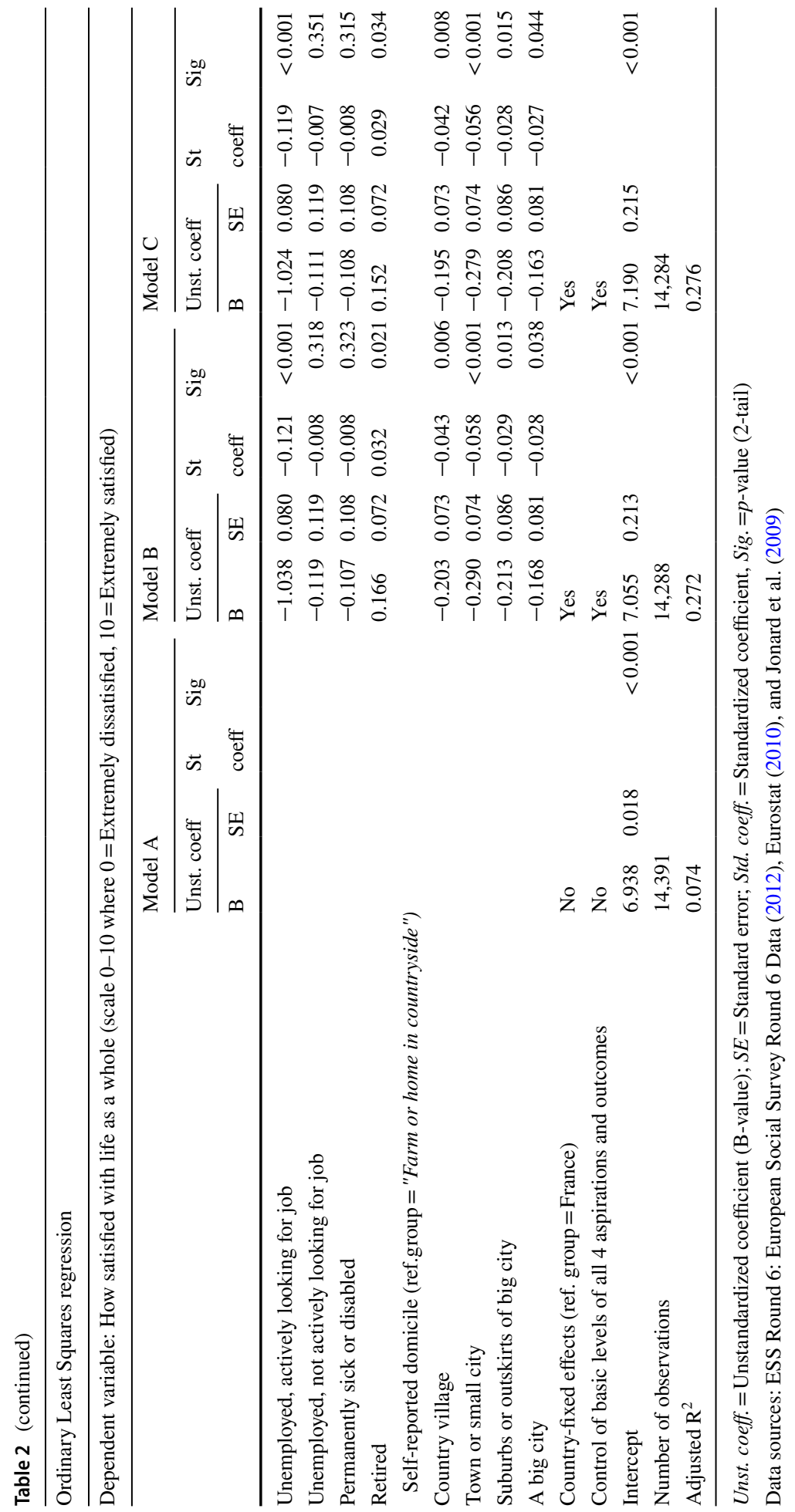


The first model (A) demonstrates that the better aspirations are met, the higher is the overall satisfaction with life, thereby corroborating the aspiration-level theory in general. In this data set, as much as $7.4 \%$ of the variation in life satisfaction can be accounted for by these four aspirational discrepancies. Among the four, the wealth gap is the strongest predictor for SWB. In practical terms, a one-unit positive increase in the gap between wealth aspiration and wealth outcome generates a 0.1 unit increase in life satisfaction (on a scale of 0 to 10). Taking into account that the total range of the wealth gap lies between -10 and +8 units (i.e., altogether 19 units), the effect size of this association appears very strong. The effect of the ambition gap is also nearly as substantial.

The following model (B), from which the four aspiration-outcome gaps are removed, is included to demonstrate the effect that individual characteristics in this data set exert on SWB. It also introduces country-fixed effects, the urban-rural dichotomy together with subjective settlement, as well as controls for the four different levels of aspiration in the equation. Now the model accounts for $27.2 \%$ of the variation in SWB. As operationalized here, urban malaise is discernible both at the structural (urban-rural typology) as well as partly at the subjective geographic level (self-reported domicile). Not unexpectedly however, the effect size of these "geographies" is nonetheless modest when compared to personal characteristics such as age, health, cohabitation status, or unemployment.

The final model $\mathrm{C}$ once more includes the four aspiration-outcome gap metrics while keeping all remaining items equal to model $\mathrm{B}$. The introduction of the four gaps raises the amount of variation explained to $27.6 \%$ in this full model C.

Aspiration-outcome gaps related to authority, and to a slightly lesser extent to success, are now the principal discrepancies associated with lower levels of life satisfaction. The strength of the former is nearly on a par with unemployment. Taking into account that involuntary unemployment has consistently been demonstrated to be one of the strongest predictors of lower SWB (cf. Dolan et al., 2008), the effect of this aspiration gap appears substantial. While the wealth in a technical sense is also still valid in this model, its practical effect, however, remains somewhat more modest. However, above all, age and subjective health still exert the strongest effect on SWB. Overall, this model nonetheless corroborates the assumptions of the second objective by demonstrating that-holding standard control variables constant-a negative discrepancy between expectations and their outcome affects SWB negatively.

As expected, the introduction of the four self-enhancement discrepancies depreciates the urban malaise aspect slightly. On average, holding all else constant, if living in any of the 32 major metropolitan areas, the SWB of these residents is lowered roughly by the same magnitude as the negative SWB effect of being a female or the positive effect of being retired does.

It is, however, still too early to conclude that these aspiration gaps would play out differently across urban and rural regions. For that, we need to analyse inhabitants in predominantly urban and other regions separately. A so-called moderated multiple regression is presented in Table 3. In this, there are separate but content-wise identical regressions for inhabitants in predominantly urban regions and for those in intermediate or predominantly rural ones. Accordingly, the dichotomous urban-rural variable itself is omitted as an explanatory factor. In all other aspects, the two models in Table 3 are duplicates of the final model $\mathrm{C}$ of Table 2, although the lower parts of the tables are not displayed here due to space constraints. Four principal observations can be made from this moderated regression.

First, although the contents of the two models are identical, the included predictors are able to explain much more variation in the SWB of the inhabitants of the 32 major metropolitan regions than for the remaining inhabitants. The coefficient of determination 
Table 3 Urban-rural differentiated SWB impact of self-enhancement gaps

Ordinary Least Squares regression

Dependent variable: How satisfied with life as a whole (scale $0-10$ where $0=$ Extremely dissatisfied, $10=$ Extremely satisfied)

\begin{tabular}{|c|c|c|c|c|c|c|c|c|}
\hline & \multicolumn{4}{|c|}{$\begin{array}{l}\text { Predominantly rural or inter- } \\
\text { mediate regions }\end{array}$} & \multicolumn{4}{|c|}{ Predominantly urban regions } \\
\hline & \multicolumn{2}{|c|}{ Unst. coeff } & \multirow{2}{*}{$\begin{array}{l}\text { St } \\
\text { coeff }\end{array}$} & \multirow[t]{2}{*}{ Sig } & \multicolumn{2}{|c|}{ Unst. coeff } & \multirow{2}{*}{$\begin{array}{l}\text { St } \\
\text { coeff }\end{array}$} & \multirow[t]{2}{*}{ Sig } \\
\hline & $\mathrm{B}$ & SE & & & B & SE & & \\
\hline \multicolumn{9}{|c|}{ Main predictors of Schwartz's self-enhancement } \\
\hline Ambition gap & 0.038 & 0.017 & 0.059 & 0.027 & -0.021 & 0.019 & -0.035 & 0.278 \\
\hline Success gap & 0.027 & 0.020 & 0.034 & 0.171 & 0.113 & 0.024 & 0.140 & $<0.001$ \\
\hline Wealth gap & 0.059 & 0.018 & 0.085 & 0.001 & 0.008 & 0.019 & 0.013 & 0.666 \\
\hline Authority gap & 0.084 & 0.018 & 0.107 & $<0.001$ & 0.090 & 0.020 & 0.128 & $<0.001$ \\
\hline $\begin{array}{l}\text { Control variables and country-fixed } \\
\text { effects as in Table } 2 \text { (but excluding } \\
\text { the urban-rural typology) }\end{array}$ & Yes & & & & Yes & & & \\
\hline Intercept & 7.175 & 0.291 & & $<0.001$ & 6.967 & 0.326 & & $<0.001$ \\
\hline Number of observations & 8,457 & & & & 5,779 & & & \\
\hline Adjusted $\mathrm{R}^{2}$ & 0.270 & & & & 0.304 & & & \\
\hline
\end{tabular}

Unst. coeff. $=$ Unstandardized coefficient $(\mathrm{B}-\mathrm{value}) ; S E=$ Standard error; Std. coeff. $=$ Standardized coefficient, Sig. = p-value (2-tail)

Data sources: ESS Round 6: European Social Survey Round 6 Data (2012), Eurostat (2010), and Jonard et al. (2009)

(adjusted $\mathrm{R}^{2}$ ) for regions of the former type amounts to 0.304 in comparison to 0.270 for inhabitants of the latter type.

Second, the average level of SWB (i.e., the intercept) for inhabitants in predominantly urban regions (6.967) is substantially lower than for the remaining less urban inhabitants (7.175), indicating urban malaise. However, as the standard errors of the intercepts are substantial, it is not possible to ascertain this unconditionally. Additionally, we do not yet know whether this difference-if any-stems from larger aspiration-outcome gaps in urban areas (i.e., the third and final objective) or if the difference could simply emerge due to differences in any of the numerous control variables. In order to ascertain this, we need to examine the individual discrepancy variables and how these play out differently across the types of regions as well as how strong an effect on subjective SWB they exert.

Thus, third, for inhabitants of predominantly urban regions, the success gap is the strongest predictor of SWB among the four, while the authority gap also exerts a substantial effect. Contrary to Stutzer's (2004) findings, the wealth gap does not appear to exert any effect on SWB in these 32 metropolitan surroundings, whereas it does so moderately for inhabitants of other types of regions. However, for inhabitants of these intermediate or predominantly rural regions, the authority gap appears as the strongest predictor for life satisfaction. Additionally, the SWB of persons living in these less urbanized areas also correlates moderately with the ambition gap.

Fourth, the final observation relates to the effect sizes of the relevant variables. For inhabitants of predominantly urban regions, the effect sizes of the two relevant gaps 
(success, authority) are much stronger than the most important gaps (authority, wealth) for inhabitants of other types of regions. For inhabitants of the more urbanised regions, the effect sizes of the most influential gaps nearly reach the levels of health or unemployment.

In essence this entails that discrepancies related to self-enhancement have, on average, a stronger impact on the overall satisfaction with life of inhabitants of the 32 major urban areas of Western Europe than they have on the SWB of inhabitants of less urbanized surroundings in the same ten countries. This strongly suggests that urban-rural differences in the magnitude of the gap between expectations and outcome related to self-enhancement, as well as the differences in the combination of these gaps, would be able to explain some of the urban-rural differences in SWB. As such, this ultimately is in accord with the basic premise expressed in the third objective, i.e., that urban-rural differences related to selfenhancement are - for their part—an additional explanation for urban malaise.

\section{Discussion and Conclusion}

In line with aspiration-level theory, this analysis has demonstrated that the better a person's aspirations are fulfilled, the higher is his or her overall satisfaction with life. The analysis has also demonstrated that inhabitants of 32 major metropolitan regions in ten western European countries have substantially higher aspirations when it comes to self-enhancement than do their more rural counterparts. However, the level of fulfilment of these aspirations is also generally higher among these urban residents. The analysis has ultimately demonstrated that the discrepancy between aspirations and outcome affects overall assessments of subjectively reported SWB more strongly in highly urbanized areas than it does in less urbanized surroundings. The primary scientific contribution of this paper is thus that it indicates that such urban-rural differences should be added to currently dominant explanations for the phenomenon of urban malaise. In a theoreticized manner, Fig. 1 illustrates the relationship between an aspiration-outcome gap on the one hand and resulting urban-rural differences in SWB on the other.

This simple analytic model however assumes that the outcome-aspiration-SWB vector would be linear. In reality, it appears plausible to assume that these gradients would be of a logarithmic nature adhering to the process of decreasing marginal utility. This issue thus calls for further research with emphasis on non-linear techniques.

Fig. 1 Differing rural and urban aspiration gaps and their impact on SWB, Source: Author's own elaboration

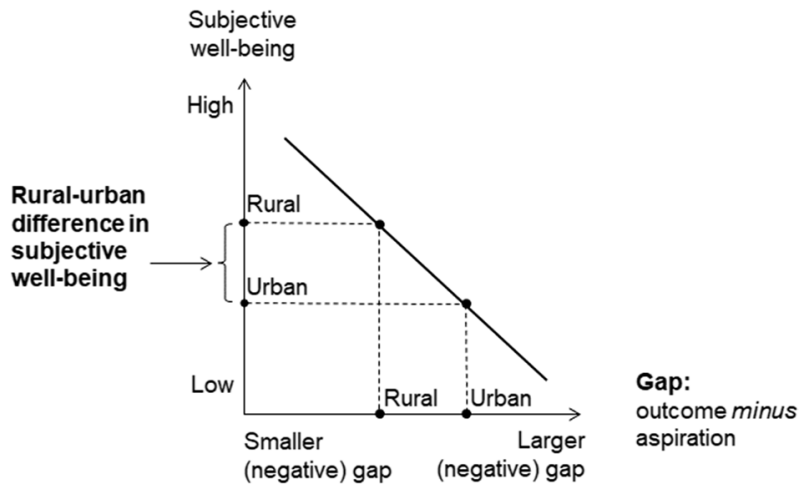


Human aspirations are most likely policy amenable only to a very marginal degree. Fostering less ambition among urban inhabitants or migrants to cities by means of public campaigns, or nurturing more "rural" values in urban communities, appears to be an extremely implausible path of development. Amplified urban aspiration levels should thus probably be considered an inherent principle of nature guiding urban life. They could be viewed on a par with aspects such as age or gender, which have a strong impact on SWB, but are utterly difficult to directly address by public policy. Accordingly, it would probably be more feasible for public policy to try to pay attention to the outcome levels instead, thereby diminishing the gap. However, whereas public policy doubtlessly would be able to affect the wealth outcome of urban residents, it remains equally uncertain what it could do about the remaining three self-enhancement outcomes (ambition, success, authority). At the least, however, it would be important to acknowledge that although the city_travestying Glaeser (2011)_might make us richer, smarter, healthier, or even greener, it does not necessarily make us happier too and, apparently, not more satisfied with our lives either.

The issue of causality calls for attention. Based on the analysis herein, it is not possible to establish a clear causal direction between the level of aspiration fulfilment and urban environments. It may well be that cities act as magnets for persons with high aspirations in certain areas of life, thus aggravating the discrepancy. However, it may equally well be that the billboards, the neon lights, or the popular cultural image of cities in themselves are the cause of higher aspirations. Utilizing the vocabulary of Ballas and Tranmer (2012:p. 94), quality of life might be dependent not only on the contextual setting of the community, "something about the place", but also on "the characteristics of its inhabitants". As an indication of the latter-concentrating specifically on persons migrating from rural to urban areas-Cardoso et al. (2019), for example, argued that one reason for lower SWB among such migrants can be attributed to the effect that several cognitive biases exert on creating overoptimistic expectations concerning the outcome of their move.

However, some recent findings also support the notion that location has an impact on the SWB of its inhabitants. In the developed world, the prevailing neoliberal dogma based on preference fulfilment through consumption choices is more closely related to urban communities than more rural ones (Oliveira et al., 2019). Examining data for approximately a million European citizens across 27 nations and over three decades, Michel et al. (2019) found robust evidence of a negative correlation between the amount of advertising and the level of life satisfaction. Advertising creates a mental demand, which, according to the hedonic treadmill theory, in the long run is likely to remain unfulfilled.

Although there are few specific indications as to whether urban inhabitants are more exposed to advertising than rural ones, at least out-of-home advertising (i.e. printed or digital billboards) could be expected to be more of an urban concern. Also, online shopping still appears to be a predominantly urban phenomenon (Beckers et al., 2018; Farag et al., 2006), exposing urban residents more than their rural counterparts to digital advertising.

Recently, the well-established regulatory focus theory has also been used for establishing causality between settlement size and human behaviour. Stemming from psychology, the regulatory focus theory states that human goals are guided by two opposing motivating systems: promotion and prevention. Persons motivated by promotion goals focus on growth and accomplishment and tend to take risks. Persons motivated by prevention goals are risk aversive and focus on safety and security. Ross and Portugali (2018) applied this theory in a large vs. small city context and found that a large city affects a person's behaviour so that it intensifies both motivating systems, depending on the individual's personal regulatory focus. As they were, furthermore, able to demonstrate clear causality, i.e., that the size of 
the city affects the regulatory system and not the other way around, this might also constitute a tentative explanation for why urbanites have a tendency to aspire to more.

The issue of aggravated urban expectations would benefit from further interest from the scientific community. An examination of the degree of fulfilment of spheres of human aspirations other than mere self-enhancement, such as benevolence, security or conformity, might shed additional light on why rural residents tend to report higher SWB than do urban ones. In a technical sense, longitudinal analysis is needed so as to overcome the gap between present expectations and future outcome.

Perhaps even more importantly, there is a need to address inequality. The prevailing public policy discourse excessively stresses both the necessity and the societal benefits of urbanization (cf. Brenner \& Schmid, 2015; Gleeson, 2014; Soininvaara, 2020). This discourse, however, generally departs from an aggregated point of view where average performances across different types of settlements are compared. This study also falls into that category. However, as pointed out above, the positional treadmill-where people tend to compare their lives against those of others in their vicinity-exerts a strong influence on SWB. Also, in terms of fulfilled aspirations, some people get what they desire, whereas others do not. Since socioeconomic differences in general tend to be larger in urban areas, it could also be expected that the amplitude of disparity among urban inhabitants in terms of aspirations and meeting them is much larger than is the case in rural surroundings. Hence, examining not only the levels of aspiration fulfilment across different types of settlements on average, but also considering intra-regional disparities of that very same nature, may additionally clarify reasons behind urban malaise.

\section{Appendix}

See Table 4.

Acknowledgements In addition to three anonymous referees, I thank Teemu T. Kemppainen, Vesa Kanninen and Daniel Rauhut for their insightful comments on the early manuscripts of this article.

Author Contributions The author is the sole author of the article.

Funding Open Access funding provided by University of Helsinki including Helsinki University Central Hospital. This work was supported by the Academy of Finland under grant no. 315772.

Data availability The data that support the findings of this study are openly available in "NSD-Norwegian Centre for Research Data, Norway - Data Archive and distributor of ESS data for ESS ERIC “ at www.europeansocialsurvey.org, reference number ESS Round 6: European Social Survey Round 6 Data (2012). SPSS outputs of all omitted statistical analyses are available by request from the author.Code availability IBM SPSS Statistics 25 . 
Table 4 Descriptive statistics (sample population)

Type of region (\% of respondents)

"Predominantly urban" regions (32 regions)

"Intermediate" or "Predominantly rural" regions (105 regions)

Gender (\% of respondents)

Female

Male

Average age of respondents in years

Cohabitation status ( $\%$ of respondents)

Cohabiting

Not cohabiting

Average number of people living regularly as member of household

Subjective general health ( $\%$ of respondents)

1 = very bad

2

$5=$ very good

Education (\% of respondents)

Low education (ISCED I-II)

Middle education (ISCED III-IV)

High education (ISCED $\geq \mathrm{V}$ )

Other

Labour market status (\% of respondents)

In paid work

In education

Unemployed, actively looking for job

Unemployed, not actively looking for job

Permanently sick or disabled

Retired

Other

Self-reported domicile (\% of respondents)

A big city

Suburbs or outskirts of big city

Town or small city

Country village

Farm or home in countryside

Country (\% of respondents)

Belgium

Denmark

Finland

France

Ireland

Netherlands

Spain

Sweden 
Table 4 (continued)

Data sources: ESS Round 6: European Social Survey Round 6 Data (2012), Eurostat (2010), and Jonard et al. (2009)

\section{Declarations}

Conflict of interest The author declares that he has no conflict of interest.

Open Access This article is licensed under a Creative Commons Attribution 4.0 International License, which permits use, sharing, adaptation, distribution and reproduction in any medium or format, as long as you give appropriate credit to the original author(s) and the source, provide a link to the Creative Commons licence, and indicate if changes were made. The images or other third party material in this article are included in the article's Creative Commons licence, unless indicated otherwise in a credit line to the material. If material is not included in the article's Creative Commons licence and your intended use is not permitted by statutory regulation or exceeds the permitted use, you will need to obtain permission directly from the copyright holder. To view a copy of this licence, visit http://creativecommons.org/licenses/by/4.0/.

\section{References}

Acs, Z. J. (2003). Innovation and the growth of cities. Edward Elgar Publishing.

Andres, L., \& Looker, E. D. (2001). Rurality and capital: Educational expectations and attainments of rural, urban/rural and metropolitan youth. Canadian Journal of Higher Education, 31(2), 1-45.

Amos, O. M., Hitt, M. A., \& Warner, L. (1982). Life satisfaction and regional development: A case study of Oklahoma. Social Indicators Research, 11(3), 319-331.

Andrews, F. M., \& McKennell, A. C. (1980). Measures of self-reported well-being: Their affective, cognitive, and other components. Social Indicators Research, 8(2), 127-155.

Bajema, D., Miller, W. W., \& Williams, D. L. (2002). Aspirations of rural youth. Journal of Agricultural Education, 43(3), 61-71.

Ballas, D., \& Tranmer, M. (2012). Happy people or happy places? A multilevel modeling approach to the analysis of happiness and well-being. International Regional Science Review, 35(1), 70-102.

Beckers, J., Cárdenas, I., \& Verhetsel, A. (2018). Identifying the geography of online shopping adoption in Belgium. Journal of Retailing and Consumer Services, 45, 33-41.

Bergheim, S. (2008). Well-being in Germany. Its happy regions have much in common. Deutsche Bank Research, January 7, 2008.

Best, C. J., Cummins, R. A., \& Lo, S. K. (2000). The quality of rural and metropolitan life. Australian Journal of Psychology, 52(2), 69-74.

Bjørnskov, C., Dreher, A., \& Fischer, J. A. (2008). Cross-country determinants of life satisfaction: Exploring different determinants across groups in society. Social Choice and Welfare, 30(1), 119-173.

Brenner, N., \& Schmid, C. (2015). Towards a new epistemology of the urban? City, 19(2-3), 151-182.

Brickman, P., \& Campbell, D. T. (1971). Hedonic relativism and planning the good society. In M. H. Apley (Ed.), Adaptation level theory: A symposium (pp. 287-305). Academic Press.

Brickman, P., Coates, D., \& Janoff-Bulman, R. (1978). Lottery winners and accident victims: Is happiness relative? Journal of Personality and Social Psychology, 36(8), 917-927.

Burchinal, L. G. (1961). Differences in educational and occupational aspirations of farm, small-town, and city boys. Rural Sociology, 26(2), 107-121.

Campbell, A., Converse, P. E., \& Rodgers, W. L. (1976). The quality of American life. Russell Sage Foundation.

Cardoso, R., Meijers, E., van Ham, M., Burger, M., \& de Vos, D. (2019). Why bright city lights dazzle and illuminate: A cognitive science approach to urban promises. Urban Studies, 56(2), 452-470.

Cheshire, P. C. (2006). Resurgent cities, urban myths and policy hubris: What we need to know. Urban Studies, 43(8), 1231-1246.

Choi, B. M., \& Lee, J. Y. (2008). Comparison of life satisfaction between urban and rural residents. Korean Social Science Journal, 35(2), 31-54.

Dale, B. (1980). Subjective and objective social indicators in studies of regional social well-being. Regional Studies, 14, 503-515. 
Davis, E. E., \& Fine-Davis, M. (1991). Social indicators of living conditions in Ireland with European comparisons. Social Indicators Research, 25(2-4), 103-365.

Deaton, A. (2012). The financial crisis and the well-being of Americans. 2011 OEP Hicks Lecture. Oxford economic papers, 64(1), 1-26.

Dockery, A. M. (2003). Happiness, life satisfaction and the role of work: Evidence from two Australian surveys. School of economics and finance working paper no. 3. Perth: Curtin Business School.

Dolan, P., Peasgood, T., \& White, M. (2008). Do we really know what makes us happy? A review of the economic literature on the factors associated with subjective well-being. Journal of Economic Psychology, 29(1), 94-122.

Dunlop, S., Davies, S., \& Swales, K. (2016). Metropolitan misery: Why do Scots live in 'bad places to live'? Regional Studies, Regional Science, 3(1), 379-398.

Easterlin, R. A. (2001). Income and happiness: Towards a unified theory. The Economic Journal, 111(473), 465-484.

Ehrhardt, J. J., Saris, W. E., \& Veenhoven, R. (2000). Stability of life satisfaction over time. Analysis of change in ranks in a national population. Journal of Happiness Studies, 1, 177-205.

ESS Round 6: European Social Survey Round 6 Data (2012). Data file edition 2.1. NSD - Norwegian Centre for Research Data, Norway - Data Archive and distributor of ESS data for ESS ERIC.

European Social Survey (2014). Weighting European Social Survey Data. Retrieved 18 June, 2019, from https://www.europeansocialsurvey.org/docs/methodology/ESS_weighting_data_1.pdf.

Eurostat (2010). Urban/rural typology of NUTS3 regions. Retrieved 24 August, 2019, from https://ec. europa.eu/eurostat/statistics-explained/index.php/File:Urban_rural_typology_of_NUTS_3_regions.xls.

Farag, S., Weltevreden, J., Van Rietbergen, T., Dijst, M., \& van Oort, F. (2006). E-shopping in the Netherlands: Does geography matter? Environment and Planning B: Planning and Design, 33(1), 59-74.

Fischer, C. S. (1973). Urban malaise. Social Forces, 52(2), 221-235.

Florida, R. (2005). Cities and the creative class. Routledge.

Frank, R. H. (1985). Choosing the right pond: Human behavior and the quest for status. Oxford University Press.

Frey, B. S., \& Stutzer, A. (2002). Happiness and economics: How the economy and institutions affect human well-being. Princeton University Press.

Fujita, F., \& Diener, E. (2005). Life satisfaction set point: Stability and change. Journal of Personality and Social Psychology, 88(1), 158-164.

Gelman, A., Pittau, G.M., \& Zelli, R. (2008). Life satisfaction in the European Union: also a regional matter?, In: 30th General Conference of The International Association for Research in Income and Wealth, Portoroz, Slovenia, Parallel Session 7B, 24-30 August 2008.

Gerdtham, U. G., \& Johannesson, M. (2001). The relationship between happiness, health, and socio-economic factors: Results based on Swedish microdata. The Journal of Socio-Economics, 30(6), 553-557.

Gilbert, A., Colley, K., \& Roberts, D. (2016). Are rural residents happier? A quantitative analysis of subjective wellbeing in Scotland. Journal of Rural Studies, 44, 37-45.

Glaeser, E. (2011). Triumph of the city: How our greatest invention makes us richer, smarter, greener, healthier, and happier. Penguin Press.

Glaeser, E. L., Gottlieb, J. D., \& Ziv, O. (2016). Unhappy cities. Journal of Labor Economics, 34(S2), S129-S182.

Gleeson, B. (2014). The urban condition. Routledge.

Graham, C., \& Pettinato, S. (2001). Happiness, markets, and democracy: Latin America in comparative perspective. Journal of Happiness Studies, 2(3), 237-268.

Grouzet, F. M., Kasser, T., Ahuvia, A., Dols, J. M. F., Kim, Y., Lau, S., Ryan, R. M., Saunders, S., Schmuck, P., \& Sheldon, K. M. (2005). The structure of goal contents across 15 cultures. Journal of Personality and Social Psychology, 89, 800-816.

Hanell, T. (2018). Regional Quality of Life in the EU - Comprehending the European space beyond GDP through the capability approach. Aalto University publication series. Doctoral dissertations 190/2018.

Headey, B., \& Wearing, A. (1989). Personality, life events, and subjective well-being: Toward a dynamic equilibrium model. Journal of Personality and Social Psychology, 57(4), 731-739.

Howley, C. W. (2006). Remote possibilities: Rural children's educational aspirations. Peabody Journal of Education, 81(2), 62-80.

Jonard, F., Lambotte, M., Ramos, F., Terres, J. M., \& Bamps, C. (2009). Delimitations of rural areas in Europe using criteria of population density, remoteness and land cover. JRC Scientific and Technical Reports, European Commission, Joint Research Center, Institute for Environment and Sustainability. EUR, 23757.

Kahneman, D., \& Krueger, A. B. (2006). Developments in the measurement of subjective well-being. The Journal of Economic Perspectives, 20(1), 3-24. 
Kim, D. (2018). Cross-national pattern of happiness: Do higher education and less urbanization degrade happiness? Applied Research in Quality of Life, 13(1), 21-35.

Lawless, N. M., \& Lucas, R. E. (2011). Predictors of regional well-being: A county level analysis. Social Indicators Research, 101(3), 341-357.

Lenzi, C., \& Perucca, G. (2018). Are urbanized areas source of life satisfaction? Evidence from EU regions. Papers in Regional Science, 97, S105-S122.

Lipset, S. M. (1956). Social mobility and urbanization. Institute of Industrial Relations.

Lucas, R. E., Clark, A. E., Georgellis, Y., \& Diener, E. (2003). Reexamining adaptation and the set point model of happiness: Reactions to changes in marital status. Journal of Personality and Social Psychology, 84(3), 527-539.

Lucas, R. E., \& Diener, E. (2009). Personality and subjective well-being. In E. Diener (Ed.), The science of well-being (pp. 75-102). Springer.

McCray, J. W., \& Day, S. S. (1977). Housing values, aspirations, and satisfactions as indicators of housing needs. Home Economics Research Journal, 5(4), 244-254.

Mason, R., \& Faulkenberry, G. D. (1978). Aspirations, achievements and life satisfaction. Social Indicators Research, 5(1-4), 133-150.

Meadow, H. L., Mentzer, J. T., Rahtz, D. R., \& Sirgy, M. J. (1992). A life satisfaction measure based on judgment theory. Social Indicators Research, 26(1), 23-59.

Michel, C., Sovinsky, M., Proto, E., \& Oswald, A. J. (2019). Advertising as a major source of human dissatisfaction: Cross-national evidence on one million Europeans. In M. Rojas (Ed.), The economics of happiness (pp. 217-239). Springer.

Middleton, R., \& Grigg, C. M. (1959). Rural-Urban differences in aspirations. Rural Sociology, 24(4), $347-354$.

Migheli, M. (2017). Size of town, level of education and life satisfaction in Western Europe. Tijdschrift Voor Economische En Sociale Geografie, 108(2), 190-204.

Millward, H., \& Spinney, J. (2013). Urban-rural variation in satisfaction with life: Demographic, health, and geographic predictors in Halifax, Canada. Applied Research in Quality of Life, 8(3), 279-297.

Morrison, P. S. (2010). Local expressions of subjective well-being: The New Zealand experience. Regional Studies, 45(8), 1039-1058.

Morrison, P. S., \& Weckroth, M. (2018). Human values, subjective well-being and the metropolitan region. Regional Studies, 52(3), 325-337.

Okulicz-Kozaryn, A., \& Mazelis, J. M. (2016). Urbanism and happiness: A test of Wirth's theory of urban life. Urban Studies, 55(2), 349-364.

Okulicz-Kozaryn, A., \& Valente, R. R. (2018). City life: Glorification, desire, and the unconscious size fetish. In I. Kapoor (Ed.), Psychoanalysis and the GlObal (pp. 209-232). University of Nebraska Press.

Okulicz-Kozaryn, A., \& Valente, R. R. (2019). No urban malaise for Millennials. Regional Studies, 53(2), 195-205.

Oleson, M. (1990). Subjectively perceived quality of life. IMAGE J Nurs School, 22(3), 187-190.

Oliveira, G., Vidal, D. G., \& Ferraz, M. P. (2019). Urban lifestyles and consumption patterns. Sustainable cities and communities. In Encyclopedia of the UN Sustainable Development Goals, 11, 1-10.

Organ, D. W., \& Near, J. P. (1985). Cognition vs affect in measures of job satisfaction. International Journal of Psychology, 20(2), 241-253.

Oswald, A. J., \& Wu, S. (2010). Objective confirmation of subjective measures of human well-being: Evidence from the USA. Science, 327(5965), 576-579.

Pellenbarg, P. H., \& van Steen, P. J. (2011). Well-being in the Netherlands: A spatial perspective. Tijdschrift Voor Economische En Sociale Geografie, 102(5), 622-629.

Pittau, G. M., Zelli, R., \& Gelman, A. (2010). Economic disparities and life satisfaction in European regions. Social Indicators Research, 2010(96), 339-361.

Rentfrow, P. J. (2018). Geographical variation in subjective well-being. In E. Diener, S. Oishi, \& L. Tay (Eds.), Handbook of well-being (pp. 905-914). DEF Publishers.

Richins, M. L., \& Rudmin, F. W. (1994). Materialism and economic psychology. Journal of Economic Psychology, 15(2), 217-231.

Roberts, J. A., \& Clement, A. (2007). Materialism and satisfaction with over-all quality of life and eight life domains. Social Indicators Research, 82(1), 79-92.

Ross, G. M., \& Portugali, J. (2018). Urban regulatory focus: a new concept linking city size to human behaviour. Royal Society open science, 5(5), 171478.

Rossouw, S., \& Pacheco, G. (2012). Measuring non-economic quality of life on a sub-national level: A case study of New Zealand. Journal of Happiness Studies, 13(3), 439-454.

Sander, W. (2011). Location and happiness in the United States. Economics Letters, 112(3), 277-279. 
Schwartz, S. H. (1994). Are there universal aspects in the structure and contents of human values? Journal of Social Issues, 50(4), 19-45.

Schwartz, S. H. (2012). An overview of the Schwartz theory of basic values. Online Readings in Psychology and Culture, 2(1), 11.

Sewell, W. H., \& Orenstein, A. M. (1965). Community of residence and occupational choice. American Journal of Sociology, 70(5), 551-563.

Shucksmith, M., Cameron, S., Merridew, T., \& Pichler, F. (2009). Urban-Rural differences in quality of life across the European Union. Regional Studies, 43(10), 1275-1289.

Soininvaara, I. (2020). An analysis of 'global closures' and 'national openings' in the politics of urbanization. Geografiska Annaler: Series B, Human Geography, 102(4), 341-357.

Sørensen, J. F. (2014). Rural-urban differences in life satisfaction: Evidence from the European Union. Regional Studies, 48(9), 1451-1466.

Stutzer, A. (2004). The role of income aspirations in individual happiness. Journal of Economic Behavior \& Organization, 54(1), 89-109.

Veenhoven, R. (1997). Advances in understanding happiness. Revue Québécoise De Psychologie, 18(2), 29-74.

Veneri, P., \& Murtin, F. (2018). Where are the highest living standards? Measuring well-being and inclusiveness in OECD regions. Regional Studies, 53(5), 657-666.

Winters, J. V., \& Li, Y. (2017). Urbanisation, natural amenities and subjective well-being: Evidence from US counties. Urban Studies, 54(8), 1956-1973.

Zimmermann, S. (2014). The Pursuit of Subjective Well-Being through Specific Consumption Choice (August 21, 2014). Retrieved 17 February, 2020 from http://ssrn.com/abstract=2484660.

Publisher's Note Springer Nature remains neutral with regard to jurisdictional claims in published maps and institutional affiliations. 